\title{
Isolation and Characterization of Copper- and Zinc- Binding Metallothioneins from the Marine Alga Ulva compressa (Chlorophyta)
}

\author{
Antonio Zúñiga ${ }^{1,2}$, Daniel Laporte ${ }^{1, *}$, Alberto González ${ }^{1}$, Melissa Gómez ${ }^{1}$, \\ Claudio A. Sáez ${ }^{2,3}$ and Alejandra Moenne ${ }^{1, *(\mathbb{D})}$ \\ 1 Laboratory of Marine Biotechnology, Faculty of Chemistry and Biology, University of Santiago of Chile, \\ Alameda 3363, Santiago 9170022, Chile; antonio.zt@gmail.com (A.Z.); alberto.gonzalezfi@usach.cl (A.G.); \\ melissa.gomez@usach.cl (M.G.) \\ 2 HUB AMBIENTAL UPLA, Vicerrectoría de Investigación, Postgrado e Innovación, University of Playa \\ Ancha, Avenida Carvallo 270, Valparaíso 2340000, Chile; claudio.saez@upla.cl \\ 3 Laboratory of Aquatic Environmental Research, Center of Advances Studies, University of Playa Ancha, \\ Traslaviña 450, Viña del Mar 2520000, Chile \\ * Correspondence: daniel.laporte@usach.cl (D.L.); alejandra.moenne@usach.cl (A.M.)
}

Received: 23 September 2019; Accepted: 22 December 2019; Published: 25 December 2019

\begin{abstract}
In this work, transcripts encoding three metallothioneins from Ulva compressa (UcMTs) were amplified: The 5' and 3' UTRs by RACE-PCR, and the open reading frames (ORFs) by PCR. Transcripts encoding UcMT1.1 (Crassostrea-like), UcMT2 (Mytilus-like), and UcMT3 (Dreissena-like) showed a 5'UTR of 61, 71, and 65 nucleotides and a 3'UTR of 418, 235, and 193 nucleotides, respectively. UcMT1.1 ORF encodes a protein of 81 amino acids (MW $8.2 \mathrm{KDa}$ ) with 25 cysteines (29.4\%), arranged as three motifs CC and nine motifs CXC; UcMT2 ORF encode a protein of 90 amino acids (9.05 kDa) with 27 cysteines (30\%), arranged as three motifs CC, nine motifs CXC, and one motif CXXC; UcMT3 encode a protein of 139 amino acids $(13.4 \mathrm{kDa})$ with 34 cysteines $(24 \%)$, arranged as seven motifs CC and seven motifs CXC. UcMT1 and UcMT2 were more similar among each other, showing $60 \%$ similarity in amino acids; UcMT3 showed only $31 \%$ similarity with UcMT1 and UcMT2. In addition, UcMTs displayed structural similarity with MTs of marine invertebrates MTs and the terrestrial invertebrate Caenorhabtidis elegans MTs, but not with MTs from red or brown macroalgae. The ORFs fused with GST were expressed in bacteria allowing copper accumulation, mainly in MT1 and MT2, and zinc, in the case of the three MTs. Thus, the three MTs allowed copper and zinc accumulation in vivo. UcMTs may play a role in copper and zinc accumulation in $U$. compressa.
\end{abstract}

Keywords: copper and zinc; expression in bacteria; metal accumulation; metallothioneins; marine alga; Ulva compressa

\section{Introduction}

Metallothioneins (MTs) are low molecular weight proteins, of around $10 \mathrm{kDa}$, that are rich in cysteine residues allowing the binding of divalent or monovalent metal ions such as $\mathrm{Zn}^{2+}, \mathrm{Cd}^{2+}, \mathrm{Pb}^{2+}$, $\mathrm{Hg}^{2+}, \mathrm{Cu}^{1+}, \mathrm{Ag}^{1+}$, among others [1-3]. MTs participate in metal accumulation and detoxification in vertebrates, invertebrates, plants, algae, and bacteria [1-3]. Cysteine residues in MTs are usually arranged as CC, CXC, and/or CXXC motifs and they correspond to around $30 \%$ of amino acids. In vertebrates, cysteine residues in MTs are contained in two domains, $\alpha$ and $\beta$, that are separated by a linker of variable sizes. Vertebrate MTs are rich in glycine and alanine amino acids, ranging from $10 \%$ to $20 \%$ residues [2] and invertebrate and plant MTs can contain histidine and aromatic residues $[4,5]$. MTs were first discovered in horse kidney, although they have been isolated from kidney and liver 
of other mammals [6]. In mammals, such as humans and mouse, there are four MT isoforms and the linker is constituted by three amino acids [2]. In fish, such as in rainbow trout, there are two MTs and the linker is formed by four amino acids [7]. In invertebrates, there are mainly two MTs, and the cysteine-rich domains are separated by a linker of four to seven amino acids and they have been described in organisms such as the nematode Caenorhabtidis elegans [8], the gastropod Arianta arbustorum [9], the snail Helix pomatia [10,11], the mollusks Crassostrea virginica [12], Mytilus edulis [13], and Dreissena polymorpha [14] and in the equinodern Strongylocentrotus purpuratus [15]. The yeast Saccharomyces cerevisiae displays two MTs, CUP-1 and CRS5, and the linker is constituted by three amino acids [16,17]. The cyanobacteria Synechococcus sp. showed a single MT, SmtA, and the linker that separates the two cysteine-rich domains is constituted by 15 amino acids [2]. The first MT isolated in plants was wheat germ MT, the first cloned MT in plants was Mimulus guttatus MT, and the first cloned MT from marine algae was Fucus vesiculosus MT [18-20]. Plant MTs can be classified in four types corresponding to type 1,2,3, and 4 [3]. The types 1, 2, and 3 MTs have cysteine-rich domains separated by a linker of around 40 amino acids and a linker of about 15 amino acids, and they differ in the arrangement of cysteines in cysteine-rich domains [3]. Type 4 MTs have mainly a linker of around 15 amino acids [3]. In Arabidopsis thaliana, there are seven MTs corresponding to MT1a, MT1c, MT2a, MT2b, MT3, MT4a, and MT4b and in Populus trichcarpa $x$ deltoides there are six MTs corresponding to MT1a, MT1b, MT1a, MT1b, MT3a, and MT3b [21,22]. In addition, the study of algal genomes has shown that the brown macroalgae (Phaeophyceae) Fucus serratus, Ectocarpus siliculosus, and Sargassum binderi, and the red macroalgae (Rodophyceae) Chondrus crispus and Euchema denticulatum encode a single MT [3]. Red and brown algae MTs are related among each other considering the arrangement of cysteines [3]. Until now, no MTs have been cloned or characterized in green macroalgae (Chlorophyceae).

The green macroalga Ulva compressa is the dominant species in copper-polluted coastal areas of northern Chile and in other parts of the world $[23,24]$. It has been shown that the alga collected in the field accumulate copper in its tissue [23]. Furthermore, the alga cultivated in vitro with 2.5, 5, 7.5 , and $10 \mu \mathrm{M}$ for 0 to 12 days showed a linear accumulation of intracellular copper with increasing concentrations of the metal reaching a maximal accumulation of $620 \mathrm{\mu g} \mathrm{g}^{-1}$ of dry weight (DW), at day 12 with $10 \mu \mathrm{M}$ copper [25]. In addition, $U$. compressa extrudes copper ions to the extracellular medium reaching a maximal concentration at intracellular level of around $900 \mathrm{\mu g} \mathrm{g}^{-1}$ of DW [24]. In contrast, the green alga Ulva fasciata cultivated with $0.3 \mu \mathrm{M}$ copper for 14 days reached an intracellular level of copper of $2000 \mathrm{\mu g} \mathrm{g}^{-1}$ of DW suggesting that this alga may not extrude copper ions to the culture medium [26]. On the other hand, the level of MT transcripts in $U$. compressa cultivated with 7.5 and $10 \mu \mathrm{M}$ of copper increased from days 3 to 12 [24]. Thus, it is possible that accumulation of intracellular copper is mediated by MTs in U. compressa. In this sense, it has been shown that Arabidopsis thaliana plants deficient in MT1a accumulate 30\% less copper in the shoots than control plants [26] and A. thaliana mutants deleted in four MTs accumulate $45 \%$ less copper in the shoots [27]. In addition, rat fibroblasts having a deletion of MTI and MTII accumulate less copper than control cells and is subjected to an increase in oxidative stress [28]. Thus, it is possible that $U$. compressa can accumulate copper mediated by MTs. A transcriptomic analysis performed with the alga cultivated with $10 \mu \mathrm{M}$ copper for 0 and $24 \mathrm{~h}$ allowed the identification of 7 potential MTs in U. compressa and their levels increased from days 3 to 12 of metal exposure [29].

In this work, we cloned three putative U. compressa MTs previously described as Crassostrea-like, Mytilus-like, and Dreissena-like MTs [26], which were renamed UcMT1, UcMT2, and UcMT3, respectively. In this work, the ORF of each UcMT was cloned and expressed in the bacteria E. coli as a fusion protein with a glutahione-S-transferase (GST) allowing accumulation of copper and zinc in vivo. Thus, the marine alga $U$. compressa may accumulate intracellular copper and zinc through UcMTs. 


\section{Results}

\subsection{Sequences of Transcripts Encoding UcMTs}

Total RNA and mRNAs were isolated from $U$. compress $a$ cultivated with $10 \mu \mathrm{M}$ copper for three days. The 5' and $3^{\prime}$ untranslated regions (UTR) of transcripts encoding three UcMTs were amplified using RACE-PCR technique, as well as the open reading frame (ORF) using conventional PCR. UcMT1.1 transcript (formerly Crassostrea-like $m t$ ) and protein are described in Table 1 (Figure 1). It is important to mention that two other transcripts that were closely related with UcMT1.1 were isolated, corresponding to UcMT1.2 and UcMT1.3; UcMT1.2 showed a deletion of 48 nucleotides after G in position 471 of the 3'UTR region of UcMT1.1, and UcMT1.3 displayed the same deletion mentioned before and a deletion of 58 nucleotides after C in position 607 in the 3`UTR of UcMT1.1 (Figure 1). UcMT2 transcript (formerly Mytilus-like $m t$ ) and protein is described in Table 1 (Figure 2) as well as UcMT3 transcript (formerly Dreissena-like $m t$ ) and protein (Figure 3). The linker region of UcMT1.1, UcMT2, and UcMT2 correspond to, 9, 9, and 23 amino acids, respectively (Figures 1-3).

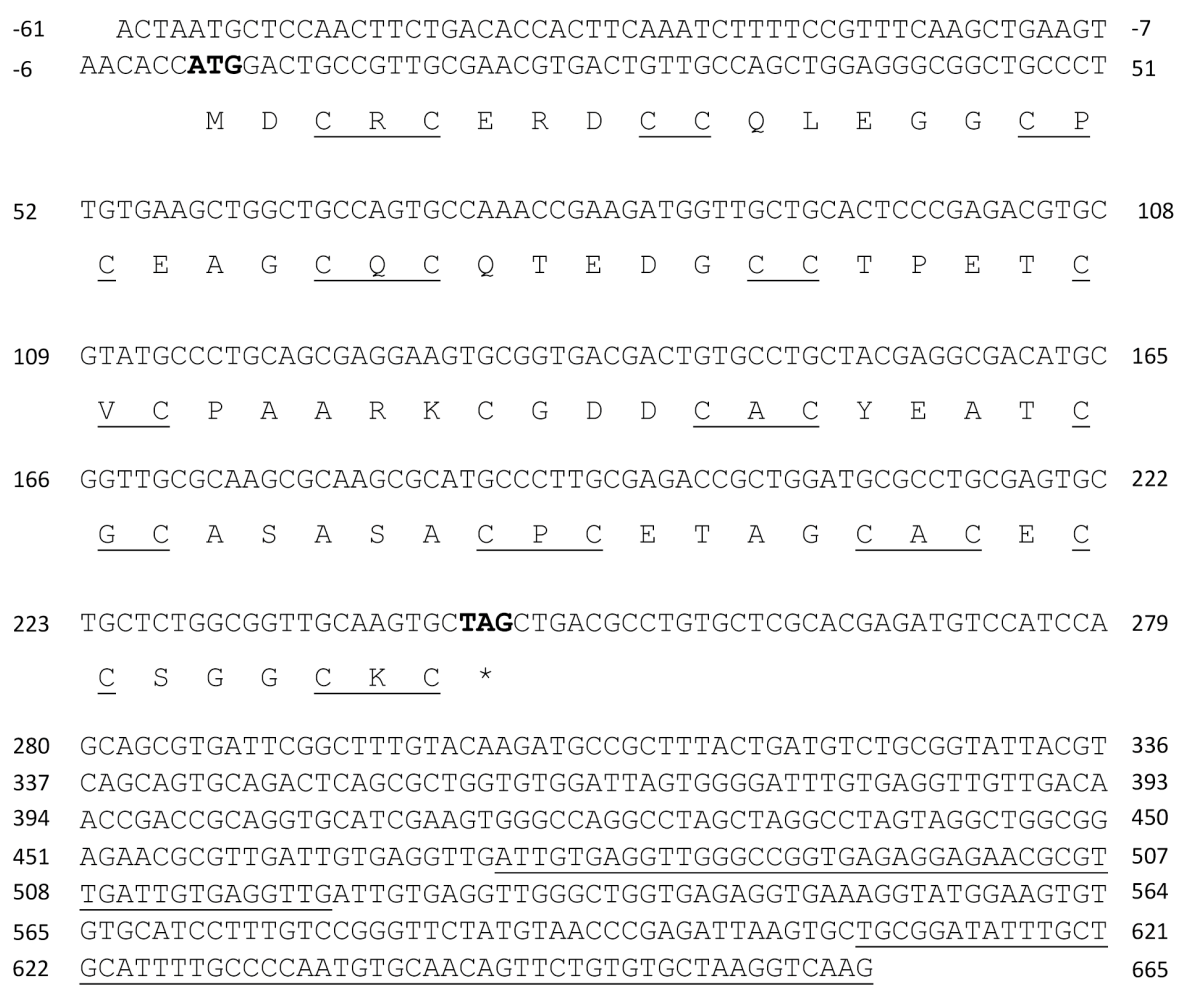

Figure 1. Complete cDNA and amino acid sequences of metallothionein UcMT1.1 (Crassostrea-like) from $U$. compressa. Initiation and termination codons are highlighted in bold; * indicate stop codon, cysteines arranged as CXC and CC motifs are underlined in the amino acid sequence of UcMT1. UcMT1.2 presents a deletion of 48 nucleotides located after the G in position 471 in the 3'UTR of MT1.1, and the deletion is underlined. UcMT3 present the deletion previously mentioned, and a deletion located after the C in position 607 in the 3'UTR of UcMT1.1, and the deletion is underlined. 
Table 1. Characteristics of $U$. compressa metallothioneins (UcMTs) transcripts and proteins. For transcripts: Nucleotides (nt); for proteins amino acids (aa) and cysteines (cys).

\begin{tabular}{lccccccccc}
\hline & $\begin{array}{c}\text { Transcript } \\
\text { (nt) }\end{array}$ & $\begin{array}{c}\mathbf{3}^{\prime} \text { UTR } \\
\text { (nt) }\end{array}$ & $\begin{array}{c}\text { ORF } \\
\text { (nt) }\end{array}$ & $\begin{array}{c}\mathbf{5}^{\prime} \text { UTR } \\
\text { (nt) }\end{array}$ & $\begin{array}{c}\text { Protein } \\
(\mathbf{a a})\end{array}$ & $\begin{array}{c}\text { MW } \\
(\mathbf{k D a})\end{array}$ & $\begin{array}{c}\text { Total } \\
\text { Cys }\end{array}$ & $\begin{array}{c}\text { \% } \\
\text { Cys }\end{array}$ & Cys Motifs \\
\hline UcMT1.1 & 726 & 61 & 246 & 418 & 81 & 8.2 & 25 & 29.4 & 3CC, 9CXC \\
UcMT2 & 580 & 71 & 273 & 236 & 90 & 9.05 & 27 & 30 & 3CC, 9CXC, 1CXXC \\
UcMT3 & 679 & 65 & 420 & 194 & 139 & 13.4 & 34 & 24 & 7CC, 7CXC \\
\hline
\end{tabular}

-71 AACCGCTGTCAACAACCGCTGTCAACACACCAACAACTCGCCAGTTCTCATATAAA -16

-15 GCATCATCTGAAGACATGGACTGCCGTTGCGACAAGGCATGCTGCCAATCCGCGgGG 42

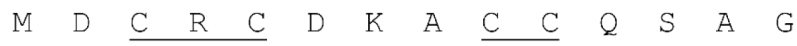

43 GAGTGCACCTGCGAGGCTGGATGCCCTTGCCATCAGGAAGGCGGTTGCTGCACTCCT 99
E $\quad C \quad T \quad C$
E A
C P C
$\begin{array}{llllllllll}H & Q & E & G & G\end{array}$
$\begin{array}{llll}C & T & P\end{array}$

100

GAGACCTGCACTTGCTCAGTGTCCAAGAAGTGTCTCGACACCTGCGCCTGCAAGACC 156

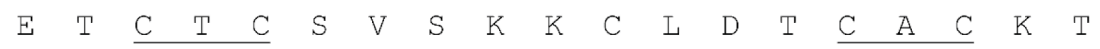

157 ACCGATGAGGGCTGTCCTTGCTCACCCGCGAAGGATTGCCCGTGCGGTACCGCCGAG

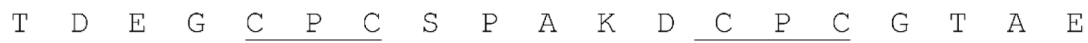

214 TGCGGCTGCGCCTGCTGCAATGATGGCTGCGACTGTACAGCCTGTCCGGGTTGTGTG

270

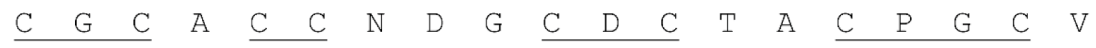

271

TAGCTCGTTCGTAGAGCTGTCTGAAGATCGTCGGCTATGTCGTTACGCAGACGCCAG

328 CATGGTCGACTAAGGACGCTGCTTGTTAGGCCTCAGTGGTTGACAGCAACTTCTGCT

384

385 TtCCAGAGATGTAATATGTCTTTTGTTCAATACCATGgTATTGACTATACAGTGGAG

442 TAGGCATGCTGGCGGGCACGGGCTGTCTGCGATGATTCGTCGAGATGGTTTGTAACT

441

499 CGGGTGAAGCC

498

Figure 2. Complete cDNA and amino acid sequences of metallothionein UcMT2 (Mytilus-like) from the marine alga $U$. compressa. Initiation and termination codons are highlighted in bold; * indicate stop codon, cysteines arranged as CXC, CC, and CXXC motifs are underlined in the amino acid sequence of UcMT2. 


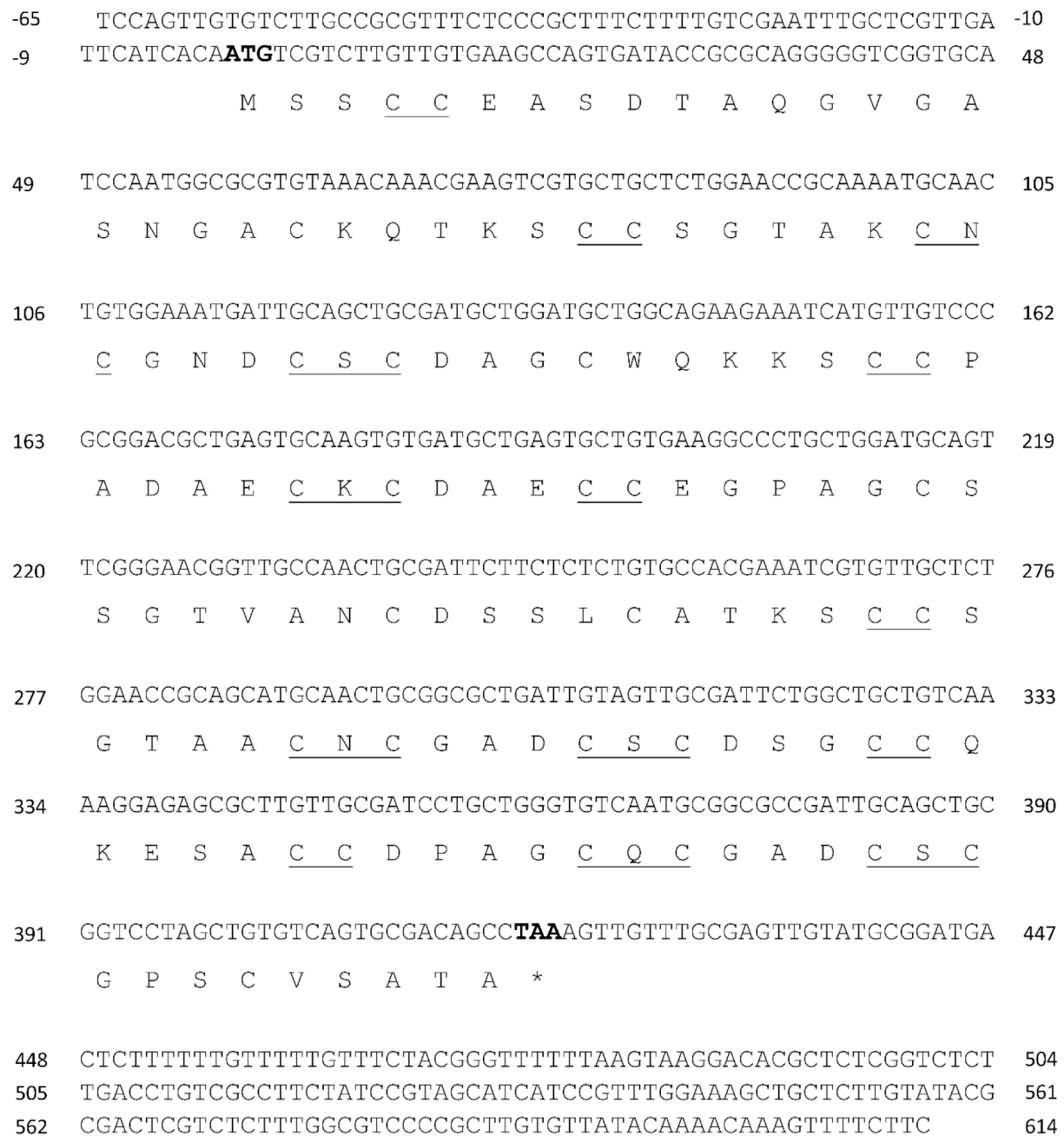

Figure 3. Complete cDNA and amino acid sequences of metallothionein UcMT3 (Dreissena-like) from the marine alga $U$. compressa. Initiation and termination codons are highlighted in bold; * indicate stop codon, cysteines arranged as CXC and CC motifs are underlined in the amino acid sequence of UcMT3.

\subsection{Similarities in Amino Acids of UcMTs and Hierarchical Clustering of MTs}

UcMT1.1 and UcMT2 were more closely related among each other and shared 52.2\% identity and $60 \%$ similarity in amino acids; indeed, both sequences contained arrangement of cysteines corresponding to 3 CC and 9 CXC motifs, but UcMT2 also contained a CXXC motif (Figure 4A). In contrast, UcMT3 shared only 30\% similarity in amino acids with MT1.1 and MT2 and contained arrangements of cysteines corresponding to 7 CC and 7 CXC (Figure 4A). UcMT3 showed an extra $\mathrm{N}$-terminal sequence of 10 amino acids, an internal additional sequence of 19 amino acids, and an extra C-terminal sequence of 8 amino acids, compared with UcMT1.1 and UcMT2 (Figure 4A). Thus, UcMT1 and UcMT2 may have derived from UcMT3 by deletions of initial, internal, and terminal nucleotide sequences.

The hierarchical clustering of vertebrate, invertebrate, and plants MTs constructed with 237 protein sequences (including the 3 UcMTs) demonstrated that UcMT1.1 and UcMT2 grouped mainly with marine crustacean MTs, such as those of the lobster Homarus americanus and the crabs Carcinus maena and Scylla serrata (Figure S1). In addition, UcMT3 clustered with the nematode C. elegans MTs, as well as with MTs of marine equinoderms MTs such as those of Sterechinus neumayeri, Strongylocentrus purpuratus, and Paracentrotus livudus (Figure S1). On the other hand, UcMTs grouped as a different clade with MTs from Rodophyceae and Phaeophyceae (Figure 4B). Thus, $U$. compressa MTs are more 
closely related with marine invertebrate MTs and the terrestrial invertebrate C. elegans MTs, and not to MTs from other marine macroalgae.

A

$\mathrm{UCMT} 1.1$

$\mathrm{UCMT} 2$

UCMT3

consensus

UCMT1. 1

UCMT2

UcMT3

consensus

UCMT1. 1

$\mathrm{UCMT2}$

UCMT3

consensus
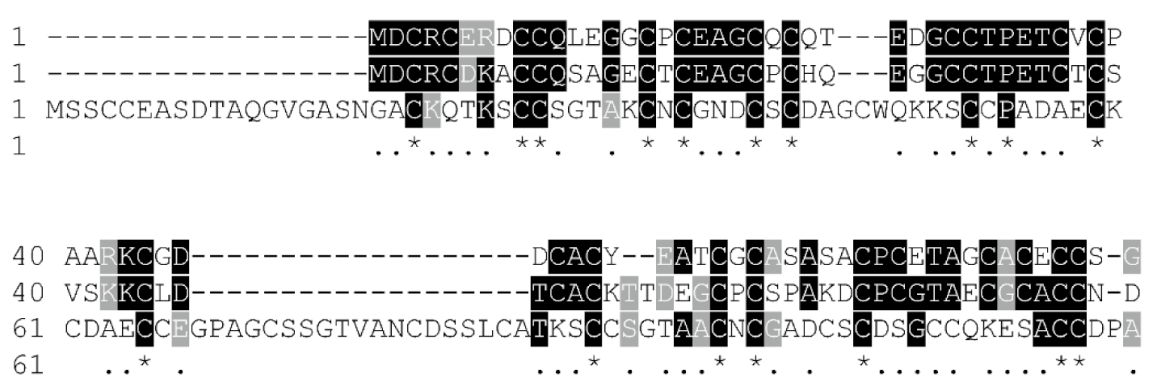

61
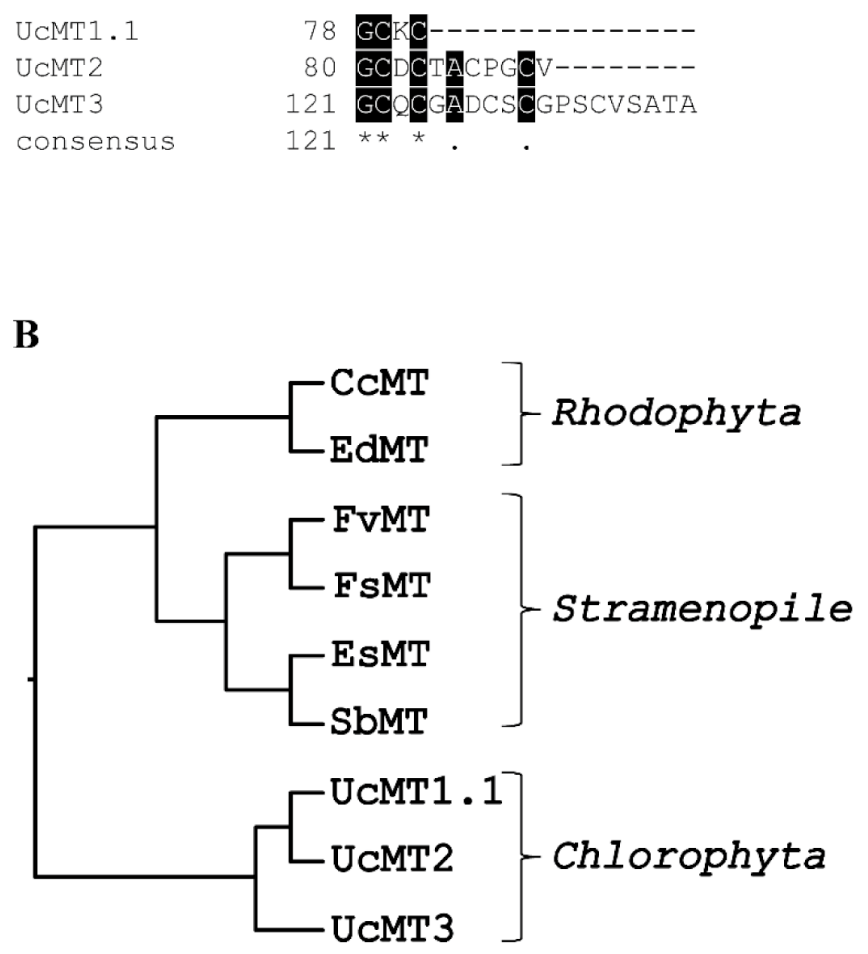

Figure 4. Alignment of amino acid sequences of metallotioneins (MTs) UcMT1.1, UcMT2, and UcMT3 from the marine alga $U$. compressa $(\mathbf{A})$. Identical amino acids are indicated in black and similar amino acids are indicated in gray. ${ }^{*}$ indicates identical amino acids and $\cdot$ similar amino acids. Hierarchical clustering of the amino acid sequences of UcMTs and MTs found in other marine macroalgae (B).

\subsection{Expression of UcMTs-GST in Bacteria and Detection of GST-Tag}

The ORFs of UcMTs were cloned in an E. coli expression vector, which allows the expression of MTs fused with the enzyme glutathione-S-transferase (GST) from the platyhelminthe Schistosoma japonicum $(26 \mathrm{kDa})$, an enzyme that contain a single cysteine in the N-terminal domain, and do not bind metals. After 1 to $12 \mathrm{~h}$ of culture, the induction of protein expression with IPTG allows the visualization of increasing levels of UcMT1.1-GST (34.2 kDa. Figure 5A), UcMT2-GST (35.05 KDa, Figure 5B), and UcMT3-GST (39.4 KDa, Figure 5C). These proteins were detected by Western blot using an antibody prepared against $S$. japonicum GST indicating that the overexpressed proteins correspond to UcMTs fused with GST (Figure 5C). 
A

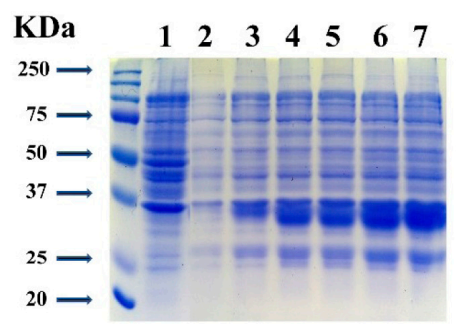

B

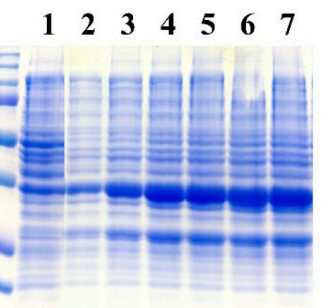

E
C

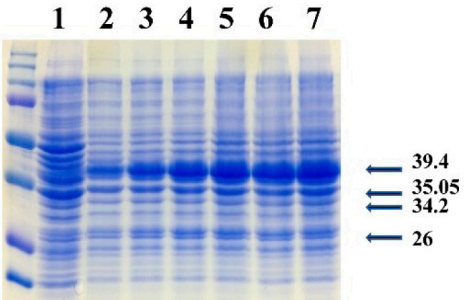

D
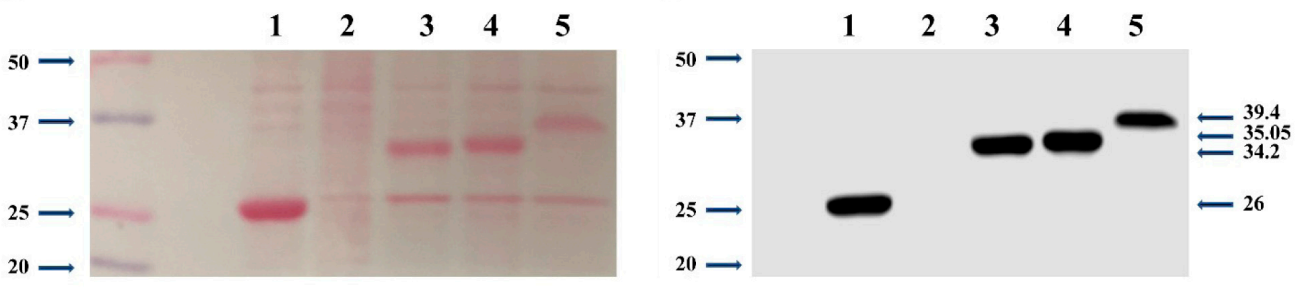

Figure 5. Visualization of protein extracts of bacteria overexpressing UcMT1.1-GST (A), UcMT2-GST (B), and UcMT3-GST (C) obtained from bacteria cultivated without IPTG (lane 1) or with $0.5 \mathrm{mM}$ IPTG for 1, 3, 6, 9, and $12 \mathrm{~h}$ (lanes 2 to 7). Visualization of proteins bacterial extracts overexpressing UcMTs-GST transferred to a nitrocellulose membrane stained with Ponceau red dye (D) or incubated with anti-GST antibody and revealed by chemiluminescence (E). Proteins of extracts overexpressing GST (lane 1), not overexpressing GST (lane 2), and overexpressing UcMT1.1-GST (lane 3), UcMT2-GST (lane 4), and UcMT3-GST (lane 5) for $6 \mathrm{~h}$. Arrows (left side) indicate molecular weights of standard proteins and arrows (right side) indicate molecular weights of UcMT3-GST (39.4 kDa), UcMT2-GST (35.05 kDa), UcMT1 (34.2 kDa), and GST (26 kDa).

\subsection{UcMTs-GST-Mediated Accumulation of Copper or Zinc In Vivo}

Transformed bacteria expressing MTs-GST were cultivated with $0.5 \mathrm{mM} \mathrm{IPTG}$ for $30 \mathrm{~min}$, and with $1 \mathrm{mM}$ copper and IPTG for $6 \mathrm{~h}$. Control bacteria expressing only GST accumulate $0.35 \mu \mathrm{g}$ of copper $\mathrm{mg}^{-1}$ of dry weight (DW), whereas those expressing UcMT1.1-GST, UcMT2-GST, and UcMT3-GST accumulate 1.8, 1.7, and 1.4 times more copper than the control, respectively (Figure 6A). On the other hand, transformed bacteria were cultivated with $0.5 \mathrm{mM}$ IPTG for $30 \mathrm{~min}$ and, with $1 \mathrm{mM}$ zinc and IPTG for $6 \mathrm{~h}$. Control bacteria accumulate $0.49 \mu \mathrm{g} \mathrm{mg}^{-1}$ of zinc mg ${ }^{-1}$ of DW whereas those expressing UcMT1.1-GST, UcMT2-GST, and UcMT3-GST accumulate 4,1, 3.8, and 3.4 times more zinc than the control, respectively; although these increases were not significantly different among each other (Figure 6A). Thus, expression of UcMTs-GST mediates accumulation of copper and zinc in vivo.

A

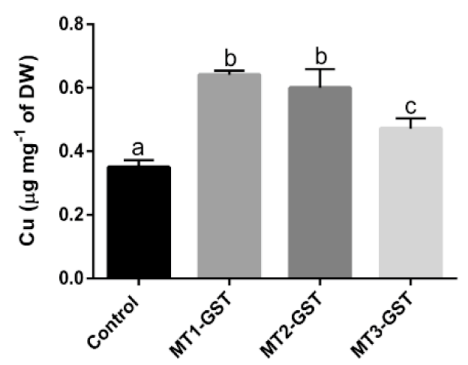

B

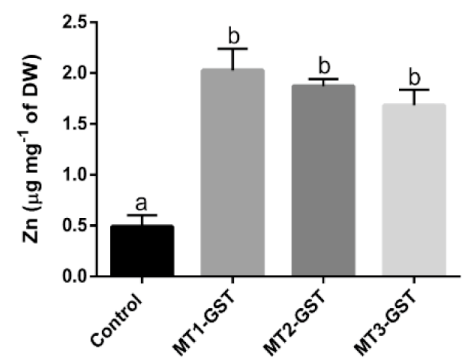

Figure 6. Level of copper (A) and zinc (B) in E. coli cultivated without IPTG for $6 \mathrm{~h}$ (control) and with $0.5 \mathrm{mM}$ IPTG for $6 \mathrm{~h}$ and overexpressing UcMT1.1, UcMT2, and UcMT3. Levels of copper and zinc are expressed in micrograms per gram of bacterial dry weight (DW). Bars represent mean values of three independent experiments \pm SD. Letters indicate significant differences among mean values $(p<0.05)$. 


\section{Discussion}

In this work, we isolated the complete sequence of transcripts encoding three MTs from the marine alga $U$. compressa. These transcripts encode UcMT1.1, UcMT2, and UcMT3 with a MW of 8.3, 9.05, and $13.4 \mathrm{kDa}$, respectively, and containing $24-30 \%$ of cysteines. It is important to mention that UcMT1.1 and UcMT2 seemed to be structurally more related among each other than to UcMT3. UcMT1.1 and UcMT2 showed deletions in amino acids sequences compared with MT3 at the initial, internal, and terminal part of the protein compared with UcMT3. Thus, UcMT2 and UcMT3 genes may have derived from UcMT3 gene. In the case of UcMT1, it seems that more than a single copy exists in $U$. compressa genome since three different transcripts of UcMT1 were isolated corresponding to UcMT1.1, UcMT1.2 and UcMT1.3. In this sense, it has been shown that the increase in number of copies of Cup1 MT gene in the yeast $S$. cereviciae allowed an increased tolerance to copper [30]. In addition, several copies of domains $\alpha$ and $\beta$ of MTs exist in the mollusk C. gigas [12]. Thus, it is not surprising that UcMT1 may be present in multiple copies in $U$. compressa genome, but the latter remained to be confirmed. The sequencing of $U$. compressa genome is already in course.

Interestingly, UcMTs resemble marine invertebrate MTs. Mollusk MTs are constituted by 73-75 amino acids and contain 20-21 cysteine residues (28\%), arranged mainly as CXC and CC motifs [5]. UcMTs are longer than mollusk MTs since they are constituted by 81,90 , and 139 amino acids; although the content of cysteines is similar to mollusk MTs (28-30\%). However, mollusk MTs reported until now do not contain histidine or aromatic residues [5]. In addition, MT from marine crustacean and equinoderms showed cysteines (29-30\%) arranged as CC and CXC and they do not contain histidine or aromatic aminoacids [25,26]. It is important to mention that we showed that UcMT1.1 contains a tyrosine, UcMT2 a histidine, and UcMT3 a tryptophan. In this sense, the two MTs found in the worm C. elegans are constituted by 75 amino acids and contain 19 cysteines (25\%), arranged as CXC and CC, and contain a tyrosine and histidine residues [8]. Thus, UcMTs are more similar to C. elegans MTs but longer and contain a higher percentage of cysteines (28-30\%). This indicates that UcMTs are unique MTs, and their sequences are more closely related with MTs of marine invertebrates and C. elegans MTs. It is not surprising that UcMTs showed similarities to marine invertebrate MTs since F. vesiculosus MT is also more related to mollusk MTs than to plant MTs [20]. F. vesiculosus MT showed a linker of 14 amino acids, which is longer than the linker of vertebrates MTs (4 aa) and the linkers of plant MTs (4 and 40 aa) [20]. The linker of UcMTs has a size of 9-13 amino acids that is more closely related with F. vesiculosus and invertebrate MTs linker size.

In addition, the sequence of UcMTs is different from the MT cloned from F. vesiculosus, which is constituted by 67 amino acids $(6.9 \mathrm{kDa})$ and contains 16 cysteine residues $(24 \%)$ arranged as CXC, but not as CC [3]. The only structural similarity of Fucus $m t$ is that this transcript showed a short $5^{\prime}$ UTR of 64 nucleotides and a long 3'UTR of 960 nucleotides [8]. Furthermore, MTs identified in the genomes of Rodophyceae C. cripus and E. denticulatum are constituted by 69 to 71 amino acids and contain 12 to 14 cysteines (20\%) arranged mainly as CXC, but not as CC [2]. Furthermore, UcMTs grouped in a different clade compared with MTs from other marine macroalgae. Thus, UcMTs of the green macroalga $U$. compressa are distantly related with those found in red and brown macroalgae.

On the other hand, we showed that UcMTs-GST mediates the accumulation of copper and zinc in bacteria. In particular, UcMT1.1 and UcMT2, which are structurally more closely related, allowed higher accumulation of copper compared with UcMT3. Moreover, the three MTs allowed accumulation of zinc with similar efficiencies among them. Thus, the three UcMTs differentially bind copper and similarly bind zinc in vivo but their affinity for copper and zinc need to be further investigated. In this sense, it has been demonstrated that MTs are either more $\mathrm{Zn}$ - or $\mathrm{Cu}$-binding thioneins, preference associated with cysteine arrangements and the nature of the other amino acids that constitute the MT [4,31]. Likewise, mouse MT1, MT2, and MT3 are more Zn-thionein and, in contrast, yeast cup-1, Drosophila MntA and MntB, and mouse MT4, are more Cu-thioneins [4,31]. Thus, the nature of UcMTs regarding their affinity for copper or zinc need to be further investigated. 
It is now clearly established that green and red macroalgae are more closely related among each other, and with terrestrial plants, than with brown macroalgae [32-34]. Green and red macroalgae belong to the kingdom Plantae, as terrestrial plants [35] whereas brown macroalgae belong to the kingdom Chromalveolta [34]. The latter is based on the observations that green and red algae contain a plastid that derive from a single event of endosymbiosis by a cyanobacteria, whereas brown algae plastids derive from a secondary or tertiary endosymbiosis event of green or red microalgae [32,33]. Thus, it is unexpected that the three UcMTs of the green macroalga $U$. compress $a$ are not closely related with other marine alga MTs, in particular to red macroalgae MTs. In contrast, the major similarity is with MTs of marine invertebrate and C. elegans MTs. Considering that marine algae appeared on earth around a billion years ago, and marine invertebrates emerged around 500 million years ago [34,36] and, moreover, that UcMTs are longer than MTs of marine invertebrates, it is then possible that marine invertebrates have acquired MTs genes from marine green macroalgae by horizontal gene transfer; however, this hypothesis need to be further investigated. Furthermore, it is possible that $U$. compressa contain additional MTs that differentially bind copper, zinc, and other heavy metals, as it has been predicted in [23], but the latter need to be further analyzed. In this sense, it has been shown that the equinoderm Paracentrotus livudus exhibits 7 MTs [35] suggesting that the four other potential UcMTs can be functional MTs. Thus, additional UcMTs may exist in the genome of $U$. compress $a$ and these MTs will be cloned and characterized in the future.

In conclusion, we showed that transcripts encoding three MTs were cloned and sequenced; they encode unique MTs with homology with marine invertebrate and C. elegans MTs. UcMTs expressed in bacteria allowed copper and zinc accumulation in vivo. Thus, it is likely that these UcMTs may participate in copper and zinc accumulation in the marine alga $U$. compressa.

\section{Materials and Methods}

\subsection{Sampling of Algae and Water Collection}

The green macroalga $U$. compressa was collected during spring 2017 from the high intertidal zone at Cachagüa Beach ( $\left.32^{\circ} 34^{\prime} \mathrm{S}\right)$, a site in central Chile with no history of metal pollution [23]. Algal samples were transported to the laboratory in sealed plastic bags inside a cool-box. In the laboratory, material was rinsed three times with filtered seawater, cleaned manually, and sonicated three times for 2 min using an ultrasound bath (HiLab Innovation Systems, model SK221OHP) to remove epiphytes. The algae were maintained in aerated seawater under an irradiance of $50 \mu$ moles $\mathrm{m}^{-2} \mathrm{~s}^{-1}$ on a photoperiod of $12 \mathrm{~h}: 12 \mathrm{~h}$ light:dark cycle, at $14^{\circ} \mathrm{C}$ for 4 days, prior to experimentation. Seawater was obtained from Quintay $\left(33^{\circ} 12^{\prime} \mathrm{S}\right)$, a pristine site in central Chile, filtered through 0.45 and $0.2 \mu \mathrm{m}$ pore size membranes and stored in darkness at $4{ }^{\circ} \mathrm{C}$.

\subsection{Algal Culture and RNA Extraction}

U. compressa ( $1 \mathrm{~g}$ of FT) was cultivated in $100 \mathrm{~mL}$ of filtrated seawater containing $10 \mu \mathrm{M} \mathrm{CuCl}_{2}$ (Merck, Darmstat, Germany) for 3 days. The alga was washed with $10 \mathrm{mM}$ Tris-50 mM EDTA pH 7.0, in order to eliminate copper and other metals bound to cell walls [37].

\subsection{Purification of Total RNAs and $m R N A$ s for RACE-PCR}

Total RNAs were extracted as described in [38]. U. compressa (150 mg of FT) was frozen in liquid nitrogen and pulverized in a mortar. One $\mathrm{mL}$ Trizol reagent (Invitrogen, Carlsbad, CA, USA) was added and the alga was homogenized with a pestle until thawing. The mixture was centrifuged at $12,000 \times g$ for $10 \mathrm{~min}$ at $4{ }^{\circ} \mathrm{C}$, and the supernatant was recovered. Chloroform $(200 \mu \mathrm{L})$ was added and the mixture was vortexed for $10 \mathrm{~s}$ and left at room temperature for $3 \mathrm{~min}$. The mixture was centrifuged at $12,000 \times g$ for $15 \mathrm{~min}$ at $4{ }^{\circ} \mathrm{C}$, and the aqueous phase was recovered. Isopropanol $(500 \mu \mathrm{L})$ was added and the solution incubated for $10 \mathrm{~min}$ at room temperature. The solution was centrifuged at $12,000 \times$ $g$ for $10 \mathrm{~min}$ at $4{ }^{\circ} \mathrm{C}$, and the supernatant removed. The pellet was washed twice with $1 \mathrm{~mL}$ of $75 \%$ 
ethanol, gently vortexed, and centrifuged at $7000 \times g$ for $5 \mathrm{~min}$ at $4{ }^{\circ} \mathrm{C}$. The ethanol phase was removed, the pellet dried for $15 \mathrm{~min}$ at room temperature, dissolved in $50 \mu \mathrm{L}$ of ultrapure water treated with DEPC (water-DEPC), and incubated for $10 \mathrm{~min}$ at $60^{\circ} \mathrm{C}$.

Total RNAs were quantified using Nanodrop spectrophotometer (Tecan, Zürich, Switzerland); the integrity was verified by agarose gel electrophoresis and stored at $-80^{\circ} \mathrm{C}$. Messenger RNAs were purified from $100 \mu \mathrm{g}$ of total RNA using NucleoTrap mRNA minikit (Macherey-Nagel, Düren, Germany), mRNAs were eluted in $25 \mu \mathrm{L}$ of water-DEPC, and normally $1 \mu \mathrm{g}$ of mRNAs was obtained from $100 \mu \mathrm{g}$ of total RNAs.

\subsection{Amplification of $5^{\prime} R A C E$ cDNAs}

The amplification of cDNAs was performed using MMLV reverse transcriptase kit (Promega, Madison, WI, USA). To this end, $4.1 \mu \mathrm{L}$ of purified mRNAs (150 ng) were mixed with $2.5 \mu \mathrm{L}$ of primer 1 for MT1 (5'GTAGCAGGCACAGTCGTCA3'), primer 2 for MT2 (5'AGGCCTAACAAGCAGCGTCC3'), or primer 3 for MT3 (5'CCGAGAGCGTGTCCTTACTT3') at $10 \mu \mathrm{M}$, and $8.4 \mu \mathrm{L}$ of water-DEPC were added to complete a final volume of $15 \mu \mathrm{L}$. The mixture was denatured at $65^{\circ} \mathrm{C}$ for $5 \mathrm{~min}$ and cooled on ice for $1 \mathrm{~min}$. Then, $0.7 \mu \mathrm{L}$ of RNase inhibitor $\left(10 \mathrm{U}_{\mu} \mathrm{L}^{-1}\right), 5 \mu \mathrm{L}$ of MMLV buffer $5 \times, 1.5 \mu \mathrm{L}$ of dNTPs mixture (10 mM of each dNTP), $1 \mu \mathrm{L}$ de MMLV reverse transcriptase $\left(200 \mathrm{U}_{\mu} \mathrm{L}^{-1}\right)$, and 1.8 $\mu \mathrm{L}$ of water- DEPC were added to complete a final volume of $25 \mu \mathrm{L}$. The mixture was sequentially incubated at $42{ }^{\circ} \mathrm{C}$ for $50 \mathrm{~min}$, at $50^{\circ} \mathrm{C}$ for $10 \mathrm{~min}$, at $55^{\circ} \mathrm{C}$ for $5 \mathrm{~min}$, and at $70{ }^{\circ} \mathrm{C}$ for $10 \mathrm{~min}$ in order to inactivate MMLV reverse transcriptase. cDNAs were treated with RNAse $H$, purified using GEL/PCR purification mini kit (Favorgen Biotech Corp., Changzhi, Taiwan), and eluted in $40 \mu \mathrm{L}$ of water-DEPC.

Purified cDNAs $(14.5 \mu \mathrm{L})$ were incubated with $0.5 \mu \mathrm{L}$ of terminal transferase (TdT), $20 \mathrm{U} \mu \mathrm{L}^{-1}$, New England Biolabs, Ipswich, MA, USA), $1 \mu \mathrm{L}$ of dCTP, $2 \mu \mathrm{L}$ of $\mathrm{CoCl}_{2}(2.5 \mathrm{mM})$, and $2 \mu \mathrm{L}$ of TdT buffer $10 \times$, to complete a final volume of $20 \mu \mathrm{L}$. The mixture was incubated at $37^{\circ} \mathrm{C}$, and at $75^{\circ} \mathrm{C}$ for 20 min to inactivate TdT in order to obtain cDNAs having a 3' C-tail.

The first round of amplification was performed using PCR kit (Favorgene, London, UK) and $1 \mu \mathrm{L}$ of C-tailed cDNAs mixed with $10 \mu \mathrm{L}$ of PCR mixture, $0.6 \mu \mathrm{L}$ of $5^{\prime} \mathrm{RACE}$ adapter primer (5'GGCCACGCGTCGACTAGTACGGGIIGGGIIGGGIIG3'), and with $0.6 \mu \mathrm{L}$ of primer 4 for MT1 (5'GGCATACGCACGTCTCGGG3'), primer 5 for MT2 (5'CTGCGTAACGACATAGCCGA3'), or primer 6 for MT3 (5'GCAGCCAGAATCGCAACTAC3'), at $10 \mu \mathrm{M}$, and $6.8 \mu \mathrm{L}$ of water-DEPC to complete a final volume of $20 \mu \mathrm{L}$. The mixture was incubated at $95{ }^{\circ} \mathrm{C}$ for $3 \mathrm{~min}$ and subjected to 40 cycles of denaturation at $95{ }^{\circ} \mathrm{C}$ for $5 \mathrm{~s}$, hybridization at $63{ }^{\circ} \mathrm{C}$ for $10 \mathrm{~s}$ and amplification at $72{ }^{\circ} \mathrm{C}$ for $15 \mathrm{~s}$, using a real-time thermocycler RotorGene 6000 . The second round of amplification was performed with the mixture diluted 100 times in distilled water-DEPC, and $14.4 \mu \mathrm{L}$ of the cDNAs were mixed with $10 \mu \mathrm{L}$ of PCR mixture, $0.6 \mu \mathrm{L}$ of abridged universal adaptor primer (AUAP) (5'GGCCACGCGTCGACTAGTAC3') and primer 7 for MT1, (5'GCAACCATCTTCGGTTTGGC3'), primer 8 for MT2, (5' ATCCTTCGCGGGTGAGCAAG3'), and primer 9 for MT3 (5'CACAGTTGCATTCTGCGGTT3') at $10 \mu \mathrm{M}$ and with $6.8 \mu \mathrm{L}$ of water-DEPC to complete a final volume of $20 \mu \mathrm{L}$. The amplification was performed using 40 cycles of amplification mentioned before. The amplified fragments were analyzed in a $2 \%$ agarose gel, stained with SYBR green (Invitrogen, Carlsbad, CA, USA), and visualized on a UV trans-illuminator.

\subsection{Amplification of $3^{\prime} R A C E c D N A s$}

Initial cDNAs were obtained using MMLV reverse transcriptase kit (Promega, Madison, WI, USA). To this end, $6.8 \mu \mathrm{L}$ of mRNAs ( $250 \mathrm{ng}$ ) were mixed with $5 \mu \mathrm{L}$ of $3^{\prime} \mathrm{RACE}$ adapter primer with an oligo-dT tail (5'GGCCACGCGTCGACTAGTACTTTTTTTTTTTTTTTTT3') at $10 \mu \mathrm{M}$ and with $3.2 \mu \mathrm{L}$ of water-DEPC to complete a final volume of $15 \mu \mathrm{L}$. The mixture was denatured at $65^{\circ} \mathrm{C}$ for $5 \mathrm{~min}$ and then cooled on ice for $1 \mathrm{~min}$. Then, $0.7 \mu \mathrm{L}$ of RNAse inhibitor $\left(10 \mathrm{U} \mu \mathrm{L}^{-1}\right), 5 \mu \mathrm{L}$ of MMLV buffer $5 \times$, $1.5 \mu \mathrm{L}$ of dNTPs mixture (10 mM of each dNTP), $1 \mu \mathrm{L}$ de MMLV reverse transcriptase $\left(200 \mathrm{U}_{\mu \mathrm{L}}^{-1}\right)$, and $1.8 \mu \mathrm{L}$ of water- DEPC were added to complete a final volume of $25 \mu \mathrm{L}$. The mixture was incubated 
at $42{ }^{\circ} \mathrm{C}$ for $1 \mathrm{~h}$ and at $70{ }^{\circ} \mathrm{C}$ for $10 \mathrm{~min}$ to inactivate MMLV reverse transcriptase and diluted to $50 \mu \mathrm{L}$ with water-DEPC. cDNAs were treated with RNAse $\mathrm{H}$, purified using GEL/PCR purification mini kit (Favorgen Biotech Corp., Changzhi, Taiwan), and eluted in $40 \mu \mathrm{L}$ of water-DEPC.

The first round of amplification was performed using PCR kit (Favorgene, London, UK) and $1 \mu \mathrm{L}$ of cDNAs were mixed with $0.6 \mu \mathrm{L}$ of AUAP ( $5^{\prime}$ GGCCACGCGTCGACTAGTAC $\left.3^{\prime}\right), 0.6 \mu \mathrm{L}$ of primer 10 for MT1 (5'CAGTGCCAAACCGAAGATGG3'), primer 11 for MT2 (5'GATGAGGGCTGTCCTTGCTC3'), or primer 12 for MT3 (5'AGTGTGATGCTGAGTGCTGT3') at $10 \mu \mathrm{M}$ and $6.8 \mu \mathrm{L}$ of water-DEPC to complete a final volume of $20 \mu \mathrm{L}$. The mixture was incubated at $95^{\circ} \mathrm{C}$ for $3 \mathrm{~min}$ and subjected to 40 cycles of denaturation at $95^{\circ} \mathrm{C}$ for $5 \mathrm{~s}$, hybridization at $63^{\circ} \mathrm{C}$ for $10 \mathrm{~s}$, and amplification at $72{ }^{\circ} \mathrm{C}$ for $15 \mathrm{~s}$, using a real-time thermocycler RotorGene 6000 . The second round of amplification was performed with the mixture diluted 100 times in distilled water-DEPC, and $14.4 \mu \mathrm{L}$ of the cDNAs were mixed with $10 \mu \mathrm{L}$ of PCR mixture, $0.6 \mu \mathrm{L}$ of AUAP forward (5'GGCCACGCGTCGACTAGTAC3') and with primer 13 for MT1 (5'GGTTGCAAGTGCTAGCTGAC3'), primer 14 for MT2 (5'GCTTGTTAGGCCTCAGTGGT3'), or primer 15 for MT3 (5'TGTCAGTGCGACAGCCTAA3') and with $6.8 \mu \mathrm{L}$ of water-DEPC to complete a final volume of $20 \mu \mathrm{L}$. The amplification was performed using 40 cycles of amplification mentioned before. The amplified fragments were analyzed in a $\%$ agarose gel, stained with SYBR green (Invitrogen, Carlsbad, CA, USA) and visualized on a UV trans-illuminator.

\subsection{Amplification of UcMT ORFs}

MT1.1 ORF was amplified using primer 16 forward (5'ATGGACTGCCGTTGCG3') and primer 17 reverse (5'GCACTTGCAACCGCCAGAGC3'); MT2 ORF was amplified using primer 18 forward (5'ATGAACTGCTGTTGCGA3') and primer 19 reverse (5'GACACAGCCCGGACAGGC3'); and MT3 ORF was amplified using primer 20 forward (5'ATGTCGTCTTGTTGTGAAGC3') and primer 21 reverse ( $5^{\prime}$ GGCTGTCGCACTGACACAG3'). The mixture was incubated at $95^{\circ} \mathrm{C}$ for $2 \mathrm{~min}$ and subjected to 35 cycles of denaturation at $95^{\circ} \mathrm{C}$ for $15 \mathrm{~s}$, hybridization at $65^{\circ} \mathrm{C}$ for UcMT1.1, $63{ }^{\circ} \mathrm{C}$ for MT2 and $62{ }^{\circ} \mathrm{C}$ for UcMT3, during $10 \mathrm{~s}$, and amplification at $72{ }^{\circ} \mathrm{C}$ for $15 \mathrm{~s}$, using a real-time thermocycler RotorGene 6000.

\subsection{Cloning of UcMTs 5' and $3^{\prime} U T R s$, and UcMT ORFs in $p G E M-T$ Vector}

The 5'RACE and 3'RACE amplification fragments obtained in the second PCR (see above) and those of UcMTs ORFs were subjected to electrophoresis in $2 \%$ agarose gel. The piece of agarose gel containing the stained fragments was removed from the gel and placed in Eppendorf tubes. The amplified fragments were eluted from agarose using Gel/PCR purification kit (Favorgen, London, $\mathrm{UK})$, recovered in $50 \mu \mathrm{L}$ of water-DEPC and stored at $4{ }^{\circ} \mathrm{C}$. Amplified fragments were ligated with the cloning vector pGEM-T easy (Promega, Madison, WI, USA) and transformed in E. coli competent cells One Shot TOP 10 (Invitrogen, Carlsbad, CA, USA). Transformed E. coli cells were cultivated in $10 \mathrm{~mL}$ of LB medium ( $10 \mathrm{~g}$ tryptone, $5 \mathrm{~g}$ yeast extract, and $100 \mathrm{~g} \mathrm{NaCl}$ in $1 \mathrm{~L}$ of distilled water) supplemented with $100 \mu \mathrm{g} \mathrm{mL} \mathrm{m}^{-1}$ of ampicillin. The culture was centrifuged at 3,000 $\mathrm{xg}$ for $5 \mathrm{~min}$ in a centrifuge model Nuwind (Nuaire, Plymouth, MN, USA). Transformed pGEM-T vectors were purified from the bacterial pellet using Wizard Plus SV Miniprep DNA Purification System (Promega, Madison, WI, USA). To check cloning of $5^{\prime}$ UTR fragments in PGEM-T, primers AUAP and primers 7, 8, and 9 were used. To check cloning of $3^{\prime} \mathrm{UTR}$ in PGEM-T, primer AUAP and primers 13, 14, and 15 were used. PCR conditions were identical to those used for the amplification of $5^{\prime}$ and $3^{\prime}$ RACE ends (mentioned above). To amplify the ORFs, primers 16 and 17 for MT1, primers 18 and 19 for MT2, and primers 20 and 21 for MT3 were used and to verify the insertion PCR conditions were those used to amplify ORFs (mentioned above). Cloned fragments were sequenced using an ABI3730XL (Macrogen, Seoul, Korea).

\subsection{Cloning of UcMTs ORFS in pGEX Expression Vector}

UcMTs were synthesized and subjected to codon optimization for expression in E. coli by Genscript (Piscataway, NJ, USA) and then ligated to the expression vector pGEX-5X-1 (Genscript) which allowed 
fusion of UcMTs ORFS with the enzyme glutahione-S-transferase (GST) from the platyhelminthes Schistosoma japonicum ( $26 \mathrm{Kda}$ ), an enzyme containing a single cysteine that does not bind metals; the fusion proteins were named UcMT1.1-GST, UcMT2-GST, and UcMT3-GST. The recombinant vectors were sequenced by Genscript to verify the correct insertion of complete ORFs.

\subsection{Transformation of Expression Vectors in Bacteria}

The recombinant expression vectors were transformed in competent E. coli strain BL21 (DE3) (Sigma-Aldrich, Saint Louis, MO, USA). To this end, $200 \mu \mathrm{L}$ of competent cells BL21 (DE3) were incubated with $50 \mathrm{ng}$ of recombinant expression vector containing UcMTs-GST. Then, $800 \mu \mathrm{L}$ of SOC medium $(2 \%(w / v)$ tryptone, $0.5 \%(w / v)$ of yeast extract, $10 \mathrm{mM} \mathrm{NaCl}, 2.5 \mathrm{mM} \mathrm{KCl}, 10 \mathrm{mM} \mathrm{MgCl} 2$, $10 \mathrm{~mm} \mathrm{MgSO}$, and $20 \mathrm{mM}$ glucose) were added, and cultivated at $37^{\circ} \mathrm{C}$ for $45 \mathrm{~min}$. An aliquot of $200 \mu \mathrm{L}$ was cultured on solid LB medium containing $100 \mu \mathrm{g} \mathrm{L}^{-1}$ of carbenicillin in a Petri dish overnight. Individual colonies were selected for each UcMT, cultivated with LB medium, and stored at $-80{ }^{\circ} \mathrm{C}$ in LB medium containing $15 \%$ glycerol.

\subsection{Expression of UcMTs-GST in Bacteria}

Recombinant E. coli were cultured $15 \mathrm{~mL}$ of $\mathrm{LB}$ medium until $\mathrm{OD}_{600}=0.6,0.5 \mathrm{mM}$ of isopropyl- $\beta$-D-1thiogalactopyranoside (IPTG) was added, and samples of $1 \mathrm{~mL}$ were obtained after 1 , $3,6,9$, and $12 \mathrm{~h}$ of culture at $37^{\circ} \mathrm{C}$. The samples were centrifuged at $7000 \times g$ for $10 \mathrm{~min}$, washed with PBS pH 7.4 (10 mM Na $\left.2 \mathrm{HPO}_{4}, 1.8 \mathrm{mM} \mathrm{KH}_{2} \mathrm{PO}_{4}, 140 \mathrm{mM} \mathrm{NaCl}, 2.7 \mathrm{mM} \mathrm{KCl}\right)$, and centrifuged again in similar conditions. Pellets were suspended in $50 \mu \mathrm{L}$ of protein loading buffer $2 \times(125 \mathrm{mM}$ Tris $\mathrm{HCl}$ $\mathrm{pH}=6.8,4 \%(w / v)$ SDS, 20\% (v/v) glycerol, 10\% (v/v) $\beta$-mercaptoethanol, $0.004 \%(w / v)$ bromophenol blue), and heated at $95{ }^{\circ} \mathrm{C}$ for $5 \mathrm{~min}$. A sample of $10 \mu \mathrm{L}$ was analyzed in a denaturant polyacrylamide gel $(12 \%)$ and proteins were stained with Coomassie blue staining solution $(25 \%(v / v)$ methanol, $5 \%$ $(v / v)$ acetic acid, and $0.1 \%(w / v)$ of Comassie blue G-250).

\subsection{Purification of UcMTs-GST by Affinity Column}

A sample of $2 \mathrm{~mL}$ of $E$. coli transformed with expression vectors containing a UcMT-GST were added to $100 \mathrm{~mL}$ LB medium containing $100 \mu \mathrm{g} \mathrm{mL}-1$ ampicillin and cultured at $37^{\circ} \mathrm{C}$ overnight. A sample of $10 \mathrm{~mL}$ was added to $1 \mathrm{~L}$ of LB medium containing $100 \mu \mathrm{g} \mathrm{mL} \mathrm{m}^{-1}$ ampicillin and $0.5 \mathrm{mM}$ IPTG, in quadruplicate, until $\mathrm{OD}_{600}=0.6$ (aprox. $2.5 \mathrm{~h}$ ). The $4 \mathrm{~L}$ of culture were centrifuged at $6000 \times \mathrm{g}$ for $10 \mathrm{~min}$. The pellet was washed twice with $300 \mathrm{~mL}$ of PBS and bacteria were suspended in $10 \mathrm{~mL}$ of PBS containing $5 \mathrm{mM}$ dithiotreitol (DTT) and 1 tablet of protease inhibitor cocktail (Roche, Manheim, Germany). The bacterial suspension was sonicated for $20 \mathrm{~s}$, with $20 \mathrm{~s}$ of pause, for $5 \mathrm{~min}$. The suspension was centrifuged at $6000 \mathrm{rpm}$ for $10 \mathrm{~min}$ and supernatant was recovered. Protein concentration was determined using Bradford method [39] and adjusted with PBS-5 mM DTT (PBS-DTT) to $1 \mathrm{mg} \mathrm{mL}^{-1}$. UcMTs-GST were purified by HPLC using GSTrap HP (General Electric, Uppsala, Sweden) at 5 bars of pressure, washed with PBS-DTT, and eluted with $3 \mathrm{~mL}$ of buffer $50 \mathrm{~mL}$ Tris-HCl-10 mM GSH. Normally, 1-2 mg of purified UcMT-GST was obtained from $4 \mathrm{~L}$ of bacterial culture and proteins were quantified using Bradford method [40].

\subsection{Detection of UcMTs-GST with Anti-GST Antibody}

Transformed bacteria were cultured in $100 \mathrm{~mL}$ of LB medium until $\mathrm{OD}_{600}=0.6,0.5 \mathrm{mM}$ IPTG was added and the mixture incubated for $6 \mathrm{~h}$. The culture was centrifuged at $6000 \times \mathrm{g}$ for $5 \mathrm{~min}$, the pellet suspended in $5 \mathrm{~mL}$ of buffer PBS, and sonicated for $20 \mathrm{~s}$, with $20 \mathrm{~s}$ of pause, for $5 \mathrm{~min}$. Proteins $(20 \mu \mathrm{g})$ were separated by electrophoresis in a denaturant $12 \%$ polyacrylamide gel and transferred to a nitrocellulose membrane for $10 \mathrm{~min}$ using Trans Blot Turbo apparatus (BioRad, Hercules, CA, USA). The membrane was stained with Ponceau Red dye and washed with $10 \mathrm{~mL}$ of distilled water. The membrane was incubated in $10 \mathrm{~mL}$ TTBS (20 mM Tris- $\mathrm{HCl} \mathrm{pH} 7.5,0.1 \mathrm{mM} \mathrm{NaCl}, 0.05 \%$ Tween-20) containing $5 \%$ skim milk for $1 \mathrm{~h}$, washed twice with $10 \mathrm{~mL}$ TTBS for $15 \mathrm{~min}$, incubated with $10 \mathrm{~mL}$ TTBS 
containing 3\% skim milk and the antibody anti-GST (Sigma-Aldrich, St Louis, MO, USA) diluted 5000 times, and washed four times in TTBS for $15 \mathrm{~min}$. The membrane was incubated in TTBS containing 3\% skim milk and the secondary antibody prepared against rabbit IgG coupled to hoseradish peroxidase (Agrisera, Vännas, Sweden) diluted 2000 times, for $1 \mathrm{~h}$, and washed four times with TTBS for 15 min. Proteins were detected using ECL Western Blotting System kit (Amersham, Buckinghamshire, UK) and revealed using a C-Digits chemiluminiscence Western blot scanner Li-Cor (Lincoln, NE, USA) and Image Studio Digits software version 4.0 Li-Cor.

\subsection{Quantification of Copper and Zinc in Bacteria Expressing UcMTs-GST}

Recombinant bacteria were cultured in $100 \mathrm{~mL}$ of LB medium containing $100 \mathrm{mg} \mathrm{mL}^{-1}$ of carbenecillin until $\mathrm{DO}_{600}=0.6$, with $0.5 \mathrm{mM} \mathrm{IPTG}$ for $30 \mathrm{~min}$, and with $1 \mathrm{mM} \mathrm{CuSO}_{4}$ or $1 \mathrm{mM} \mathrm{ZnCl}_{2}$ and IPTG for $6 \mathrm{~h}$. Bacterial pellets showed a weight of 26-42 mg for copper cultures and 46-62 mg for zinc cultures. Pellets were dried at $60{ }^{\circ} \mathrm{C}$ for $48 \mathrm{~h}$, suspended in $5 \mathrm{~mL}$ of $60 \%(v / v) \mathrm{HNO}_{3}$, and incubated at $85^{\circ} \mathrm{C}$ for $2 \mathrm{~h}$. The solutions were filtered through $0.22 \mu \mathrm{m} \mathrm{MCE}$ filters (TCL, Santiago, Chile) and analyzed by flame atomic emission spectrophotometry using an atomic emission spectrophotometer ThermoFisher (Waltham, MA, USA).

\subsection{Hierarchical Clustering of UcMTs}

Amino acid sequences corresponding to MTs of different animal and plant species (234 in total) were selected from revised SwissProt repository of the UniprotKB database (www.uniprot.org). Alignment of these sequences was performed with Clustal W software with default setting. This alignment was used to generate the phylogenetic reconstruction to represent a hierarchical clustering using UPGMA algorithm based on distance. Phylogenetic and hierarchical clustering analyses were conducted using MEGA software version X [39].

\subsection{Statistical Analyses}

Statistical analyses were performed with the Prism 6 statistical package (Graph Pad software Inc., San Diego, CA, USA). Following confirmation of normality and homogeneity of variance, significant differences among treatments were determined by two-way ANOVA and Tukey's multiple comparison post-hoc test, at a 95\% confidence interval.

Supplementary Materials: Supplementary materials can be found at http://www.mdpi.com/1422-0067/21/1/153/s1.

Author Contributions: A.Z. amplified and cloned 5'and 3'UTR and ORFs of transcripts encoding UcMTs, expressed UcMTs-GST in bacteria, and analyzed copper and zinc accumulation. A.G. and M.G. purified UcMTs-GST. D.L. guided A.Z., did hierarchical clustering of MTs, Western hybridization of UcMTs-GST, and UV-VIS spectra of MTs-GST. C.A.S. revised the manuscript and participate in discussions, and A.M. designed experimental work and wrote the manuscript. All authors have read and agreed to the published version of the manuscript.

Funding: This work was financed by Fondecyt 1160013 to A.M.

Acknowledgments: We thank Luis Lemus and Cristián Vera who helped with UV-VIS spectra analyses.

Conflicts of Interest: The authors declare no conflict of interest.

\section{Abbreviations}

$\begin{array}{ll}\text { GSH } & \text { glutathione } \\ \text { GST } & \text { glutathione-S-transferase } \\ \text { MTs } & \text { metallothioneins } \\ \text { PCs } & \text { phytochelatins } \\ \text { UV } & \text { ultraviolet }\end{array}$




\section{References}

1. Cobbett, C.; Goldsbrough, P. Phytochelatins and metallothioneins: Role in heavy metal detoxification and homeostasis. Ann. Rev. Plant. Biol. 2002, 53, 159-182. [CrossRef] [PubMed]

2. Blindauer, C.A.; Leszczyszyn, O.I. Metallothioneins: Unparalleled diversity in structures and functions for metal ions homeostasis and more. Nat. Prod. Rep. 2010, 27, 720-741. [CrossRef] [PubMed]

3. Leszczyszyn, O.I.; Imam, H.T.; Blindauer, C.A. Diversity and distribution of plant metallothioneins: A review of structure, properties and functions. Metallomics 2013, 5, 1146-1169. [CrossRef] [PubMed]

4. Palacios, O.; Atrian, S.; Capdevila, M. Zn- and Cu-thioneins: A functional classification for metallothioneins. J. Biol. Inorg. Chem. 2011, 16, 991-1009. [CrossRef] [PubMed]

5. Isani, G.; Carpene, E. Metallothioneins, unconventional proteins from unconventional animals: A long journey from nematodes to mammals. Biomolecules 2014, 4, 435-457. [CrossRef] [PubMed]

6. Margoshes, M.; Vallee, B.L. A cadmium protein from equine kidney cortex. J. Am. Chem. Soc. 1957, 79, 4813-4814. [CrossRef]

7. Kille, P.; Lee, W.E.; Darke, B.M.; Winge, D.R.; Dameron, C.T.; Stephens, P.E.; Kay, J. Sequestration of cadmium and copper by recombinant rainbow trout and human metallothioneins and by a chimeric (mermaid and fishman) proteins with interchanged domains. J. Biol. Chem. 1992, 267, 8042-8049.

8. Freedman, J.H.; Slice, L.W.; Dixon, D.; Fire, A.; Rubin, S.S. The novel metallothionein genes of Caenorhabditis elegans. J. Biol. Chem. 1993, 268, 2554-2564.

9. Berger, B.; Hunziker, P.E.; Hauer, C.R.; Birchler, N.; Dallinger, R. Mass spectrometry and amino acid sequencing of two cadmium-binding metallothionein isoforms from the terrestrial gastropod Arianta arbustorum. Biochem. J. 1995, 311, 951-957. [CrossRef]

10. Berger, B.; Dallinger, R.; Gehrig, P.; Hunziker, P.E. Primary structure of a copper-binding metallothionein from the mantle tissue of the terrestrial gastropod Helix pomatia L. Biochem. J. 1997, 328, 219-224. [CrossRef]

11. Palacios, O.; Pérez-Rafael, S.; Pagani, A.; Dallinger, R.; Atrian, S.; Capdevila, M. Cognate and noncognate metal ion coordination in metal-specific metallothioneins: The Helix pomatia system as a model. J. Biol. Inorg. Chem. 2014, 19, 923-935. [CrossRef] [PubMed]

12. Jenny, M.J.; Ringwood, A.H.; Schey, K.; Warr, G.W.; Chapman, R.W. Diversity of metallothioneins in the American oyster, Crassostrea virginica, revealed by transcriptomic and proteomic approaches. Eur. J. Biochem. 2004, 271, 1702-1712. [CrossRef] [PubMed]

13. Leignel, V.; Laulier, M. Isolation and characterization of Mytilus edulis metallothionein genes. Comp. Biochem. Physiol. 2006, 142, 12-18. [CrossRef] [PubMed]

14. Engelke, J.; Hildebrandt, A. cDNA cloning and cadmium-induced expression of metallothionein mRNA in the zebra mussel Dreissena polymporpha. Biochem. Cell Biol. 1999, 77, 237-241. [CrossRef]

15. Nemer, M.; Thornton, R.D.; Stuebing, E.W.; Harlow, P. Structure, spatial and temporal expression of two sea urchin metallothionein genes, SpMTB and SpMTA. J. Biol. Chem. 1991, 266, 6586-6593.

16. Butt, T.R.; Sternberg, E.J.; Gorman, J.A.; Clark, P.; Hamer, D.; Rosenberg, M.; Crooke, S. Copper metallothionein of yeast, structure of the gene, and regulation of expression. Proc. Natl. Acad. Sci. USA 1984, 81, 3332-3336. [CrossRef]

17. Cizewski-Culotta, V.; Howard, W.; Liu, X. CRS5 encode a metallothionein-like protein in Saccharomyces cerevisiae. J. Biol. Chem. 1994, 269, 25295-25302.

18. Lane, B.; Kajioka, R.; Kennedy, T. The wheat germ $\mathrm{E}_{\mathrm{c}}$ protein is a zinc-containing metallothionein. Biochem. Cell Biol. 1987, 65, 1001-1005. [CrossRef]

19. De Miranda, J.R.; Thomas, M.A.; Thurman, D.A.; Tomsett, A.B. Metallothionein genes from the flowering plant Mimulus guttatus. FEBS Lett. 1990, 260, 277-280. [CrossRef]

20. Morris, C.A.; Nicolaus, B.; Sampson, V.; Harwood, J.L.; Kille, P. Identification and characterization of a recombinant metallothionein protein from a marine alga, Fucus vesiculosus. Biochem. J. 1999, 338, 553-560. [CrossRef]

21. Kohler, A.; Blaudez, D.; Chalot, M.; Martin, F. Cloning and expression of multiple metallothioneins from hybrid poplar. New Phytol. 2004, 164, 83-93. [CrossRef]

22. Guo, W.J.; Meetam, M.; Goldsbrough, P.B. Examining the specific contribution of individual Arabidopsis metallothioneins to copper distribution and metal tolerance. Plant Physiol. 2008, 146, 1697-1706. [CrossRef] [PubMed] 
23. Ratkevicius, N.; Correa, J.A.; Moenne, A. Copper accumulation, synthesis of ascorbate and activation of ascorbate peroxidase in Enteromorpha compressa (L.) Grev. (Chlorophyta) from heavy metal-enriched environments in northern Chile. Plant Cell Environ. 2003, 26, 1599-1608. [CrossRef]

24. Seeliger, U.; Cordazzo, C. Field and experimental evaluation of Enteromorpha sp. as a quali-quantitative monitoring organism for copper and mercury in estuaries. Environ. Pollut. Ser. 1982, 29, 197-206. [CrossRef]

25. Navarrete, A.; González, A.; Gómez, M.; Contreras, R.A.; Díaz, P.; Lobos, G.; Brown, M.T.; Sáez, C.A.; Moenne, A. Copper excess detoxification is mediated by a coordinated and complementary induction of glutahione, phytochelatins and metallothioneins in the green seaweed Ulva compressa. Plant Physiol. Biochem. 2019, 135, 423-431. [CrossRef]

26. Geddie, A.W.; Hall, S.G. The effect of salinity and alkalinity on growth and accumulation of copper and zinc in the Chlorophyta Ulva fasciata. Ecotoxicol. Environ. Saf. 2019, 203-209. [CrossRef]

27. Benatti, M.R.; Yookongkaev, N.; Meetam, M.; Guo, W.J.; Punyasuk, N.; AbuQamar, S.; Goldsbrough, P. Metallothionein deficiency impacts copper accumulation and redistribution in leaves and seeds of Arabidopsis. New Phytol. 2014, 202, 940-951. [CrossRef]

28. Tapia, L.; González-Agüero, M.; Cisternas, M.F.; Suazo, M.; Cambiazo, V.; Uauy, R.; González, M. Metallothionein is crucial for safe intracellular copper storage and cell survival at normal and supra-physiological exposure levels. Biochem. J. 2004, 378, 617-624. [CrossRef]

29. Laporte, D.; Valdés, N.; González, A.; Sáez, C.A.; Zúñiga, A.; Navarrete, A.; Meneses, C.; Moenne, A. Copper-induced overexpression of genes encoding antioxidant system enzymes and metallothioneins involve activation of CaMs, CPKs and MEK1/2 in the marine alga Ulva compressa. Aquat. Toxicol. 2016, 177, 433-440. [CrossRef]

30. Bi, X.W.; Kong, F.; Hu, H.Y.; Viu, X. Role of glutathione in detoxification of copper cadmium in yeast cells having different abilities to express Cup1 protein. Toxicol. Mech. Meth. 2007, 17, 6. [CrossRef]

31. Valls, M.; Bofill, R.; González-Duarte, R.; González-Duarte, P.; Capdevila, M.; Atrian, S. A new insight into metallothionein (MT) classification and evolution. J. Biol. Chem. 2001, 276, 32835-32843. [CrossRef] [PubMed]

32. Li, S.; Nosenko, D.; Hackett, J.D.; Bhattacharya, D. Phylogenomic analysis identifies red algal genes of endosymbiotic origin in the Chromalveolata. Mol. Biol. Evol. 2006, 23, 663-674. [CrossRef] [PubMed]

33. Chan, C.X.; Gross, J.; Yoon, H.S.; Bhattacharya, D. Red and green alga monophyly and extensive gene sharing found in a rich repertoire of red algal genes. Curr. Biol. 2011, 21, 328-333. [CrossRef] [PubMed]

34. Yoon, H.S.; Hackett, J.D.; Ciniglia, C.; Pinto, G.; Bhattacharya, D. A molecular time for the origin of photosynthetic eukaryotes. Mol. Biol. Evol. 2004, 21, 809-818. [CrossRef]

35. Ragusa, M.A.; Nicosia, A.; Costa, S.; Cittita, A.; Ginaguzza, F. Metallothionein gene family in the sea urchin Paracentrotus lividus: Gene structure, differential expression and phylogenetic analysis. Int. J. Mol. Sci. 2017, 18,812 .

36. Cary, G.A.; Hinman, V.F. Echinoderm development and evolution in the post-genomic era. Dev. Biol. 2017, 427, 203-2011. [CrossRef]

37. Hassler, C.S.; Slaveykova, V.I.; Wilkinson, K.J. Discriminating between intra- and extracellular metals using chemical extractions. Limnol. Oceanogr. Methods 2004, 2, 237-242. [CrossRef]

38. Chomczynski, P.; Sacchi, N. Single-step method of RNA isolation by acid-guanidinium-thiocyanate-phenolchloroform extraction. Anal. Biochem. 1987, 162, 156-159. [CrossRef]

39. Stecher, K.; Kniaz, L.M.; Tamurak, K. MEGA X: Molecular evolutionary genetics analysis across computing platform. Mol. Biol. Evol. 2018, 35, 1547-1549.

40. Bradford, M.M. A rapid and sensitive method for the quantification of microgram quantities of protein utilizing the principle of protein-dye binding. Anal. Biochem. 1976, 72, 248-254. [CrossRef]

(C) 2019 by the authors. Licensee MDPI, Basel, Switzerland. This article is an open access article distributed under the terms and conditions of the Creative Commons Attribution (CC BY) license (http://creativecommons.org/licenses/by/4.0/). 